\title{
Review of Core Support Capabilities of the Equipment SoS Analysis and Evaluation
}

\author{
Kai Lu ${ }^{1}$, Chenglong Nie ${ }^{1}$, Yingjie Yang ${ }^{1}$ \\ ${ }^{1}$ Ordnance Engineering College, Shijiazhuang, 050003, China.
}

Keywords: equipment system, core support capacity, evaluation parameters, review.

\begin{abstract}
Clear the connotation and concept of equipment SoS and core support capabilities. Core support capabilities for the evaluation from the evaluation parameters and evaluation methods two aspects, analyzed characteristic and research progress on the core security capabilities systematically and summarized existing research results. Through the comparison, this test pointed out deficiencies in the research at present. On this basis, from foreign military research, basic theory, system analysis and simulation technology of core support capabilities of the equipment system to propose follow-up research proposals.
\end{abstract}

\section{Introduction}

In recent years, several local high-tech war games showed that the future battlefield military action will no longer be confined to the traditional single branches operate independently or jointly fight a few branches, but branches tend to break boundaries requires electrical Armed day integrated joint operations, more emphasis on combat between a weaponry SoS and an other. The play to comprehensive ability and overall effectiveness of the equipment system not only has a relationship with equipment performance and size, but also depends on the reliability of equipment system, the accuracy of support. Reliability and security equipment system is a key element affecting the combat effectiveness of play equipment, while the core support capabilities as one of the most important piece, become the focus of this study. Core support capability of equipment system means a stable source of resources guaranteed support capabilities that under the conditions of combat operations or emergency situations, according to the needs to maintain and promptly resume fighting equipment system, needs to be controlled by the organizational support forces (independent security and wartime accompanying support), military academies, maintenance safeguard scientific research institutions, military equipment repair facility (base maintenance support and strategic support security), defense industry enterprises (high-tech security), the military warehouse, military transport agencies.

\section{Study of Equipment SoS}

\subsection{Concept Study.}

The basic meaning of the SoS is system of the system [1]. Retrieved from literature, from the initial concept SoS from Eisner in the study proposed multi-system integration, features [2] to present this term's widely used in many fields of military, natural environment, ecosystem, etc. The typical concept and definition of no less than 40 kinds of, I will not enumerate. Summary drawn therefrom may be associated with the equipment system features the following three points:

(1) The constituent units is independent and autonomous. Unlike the unit of the system, a constituent unit of SoS is capable of independent operation, can be flexibly transformed from a SoS to an another, with independent behavior and function at the time of the SoS conversion, autonomy reflects its behavior in its autonomous thinking, decision-making and action.

(2) The relationship between the units is complex and evolutive. Structure relations of SoS are multiple and evolutive. Structural relationships reflect the multiplicity of the relationship between the presence of a variety of members of the system at the same time, these relationships including cooperative relationship, the relationship between support and be supported, command and directed relationship, the relationship between control and be controlled collaborative exchange relations. 
Evolution of sexual relations between members of the system refers to perform different missions and tasks and in different stages of the structure need to build a different relationship. There is not applicable to structure relationships between all mission tasks, missions and tasks in the system implementation process, rigid structural relations will lead to performance degradation missions and tasks.

(3) The system of "emergence" from cumulative interaction between individuals and local or individual behavior, the emergence of behavior is nonlinear. "Emergence" behavior similar system with complex adaptive systems, which originated from interaction cumulative and individual local or individual behavior between the behavior of the system emerged divided into benign behavior and malignant behavior, system designers are usually benign emergence of the mind, it is conduct missions and tasks to perform system design, and the malignant behavior stems from the emergence of uncontrollable complex system interaction between individuals. Malignant behavior is a major risk factor for the emergence of the system.

Domestic study of the concept of equipment SoS is small and military encyclopedias don't include the term "equipment system," conducted to define current approximating concept can consult the "combat system." Jin Weixin [3] defined "combat system" as: "Combat SoS is a dynamic system which can adapt to an environment of threat and be constitute of sensor system, allegations system, communications system and fire system of independent characteristics, and these component systems themselves are adaptive and have separate functions, the size scalable. Compared with component systems, Combat SoS has more emergence and self-organization." By reading literature, definion is given herein: Equipment SoS is such a system that composed of several equipment systems of the corresponding operational capabilities in order to complete its operational mission.

\subsection{Connotation Analysis.}

First, as a member of the SoS, equipment SoS has the general characteristic: autonomy, connectivity, emergence. In terms of autonomy, for equipment system, in order to meet its own autonomy, autonomy of its component equipment is often abandoned and differently, that consisting systems' autonomy of equipment SoS exists is in order to meet its operational mission, therefore retained. In terms of connectivity, the communication between the various systems within the equipment SoS is dynamic, which depends on the specific tasks of each system currently. The communication is not fixed in stone, but dynamic, autonomous, open. In terms of emergence, the result caused by self performance of the equipment systems and the interactive between one system and another is always unforeseeable. The same combat mission, the same composition and the same system configuration, the outcome of the war may be diametrically opposed.

Secondly, the premise of equipment SoS's appearing is that corresponding operational command appears, we need to complete certain combat mission. From the global equipment system, we do a reasonable decomposition of combat missions, obtain the specific operational tasks executable, and then through the analysis and decomposition of specific tasks, determined to complete the combat capability of the combat missions required.

Again, the basic of equipment SoS is the existence of equipment system with corresponding functions. Starting from the bottom, by polymerizing and adjusting the construction of infrastructure conditions and equipment systems with different functions, form an organic whole with the appropriate operational capability by corresponding facilities and platform's carrying to meet the needs of the SoS mission. Decomposition is the decomposition of the mission, polymerization is the polymerization of resources and systems, and operational capability to undertake as its point plays an important role.

\subsection{Distinguish Equipment SoS and Equipment System.}

Simple artificial systems fall within the scope of the general system, which is different from a class of complex systems. It is designed to reflect the organizers' purpose, through the organization of the finite element and the creation of structural and relations, achieve some kind or some functions. Equipment system is a simple artificial system which is by the organization of limited combat equipment, and can get the foreseen output from the determined input, such as artillery fire systems, radar systems, command and control system. But the various components of the equipment SoS can 
interact with each other and be independent. The overall goal is also accomplished by independent behaviors of the various components. And the behavior of the composition systems and the interactive between them will lead to the occuring of unpredictable emergence. That is to say that there is not a corresponding output of the determined input. Missile defense SoS, air defense SoS are typical example of equipment SoS, the difference between equipment system and equipment is shown in Table 1.

Table 1 Difference between equipment system and equipment SoS

\begin{tabular}{|c|c|c|}
\hline Project & Equipment System & Equipment SoS \\
\hline Composition & Equipment and relationships & Equipment systems and interaction \\
\hline $\begin{array}{c}\text { Element } \\
\text { Relationships }\end{array}$ & $\begin{array}{l}\text { interdependent and mutually } \\
\text { reinforcing }\end{array}$ & $\begin{array}{l}\text { Interact with each other, but } \\
\text { independent }\end{array}$ \\
\hline $\begin{array}{c}\text { Simple } \\
\text { Infrastructure }\end{array}$ & Simple infrastructure and table & Dynamic evolution \\
\hline Coupling & Tightly coupled & Loosely coupled \\
\hline Complexity & $\begin{array}{l}\text { Existing the determinated } \\
\text { soluation of problems }\end{array}$ & $\begin{array}{c}\text { Complex and almost no optimization } \\
\text { Solutions }\end{array}$ \\
\hline Autonomous & $\begin{array}{l}\text { To protect the autonomy of the } \\
\text { autonomous equipment system } \\
\text { and give up the autonomy of } \\
\text { each single equipment }\end{array}$ & $\begin{array}{c}\text { Equipment systems installed } \\
\text { autonomous and the behavior } \\
\text { contributed to the achievement of the } \\
\text { overall objectives of the equipment } \\
\text { system }\end{array}$ \\
\hline Connectivity & $\begin{array}{l}\text { Advance with structural design, } \\
\text { among single loaded with good } \\
\text { connectivity }\end{array}$ & $\begin{array}{l}\text { Equipment system establish a } \\
\text { connection dynamically }\end{array}$ \\
\hline Emergence & $\begin{array}{l}\text { No emergence of resistance and } \\
\text { the result can be predicted }\end{array}$ & $\begin{array}{c}\text { The interaction between the system and } \\
\text { the system equipment can lead to } \\
\text { unpredictable results }\end{array}$ \\
\hline
\end{tabular}

\section{Status of Core Support Capability Research}

\subsection{Concept Study.}

(1) Foreign Research Status

At present, the main foreign research work of the core support capabilities is around the determination of the concept and evaluation parameters. Due to differences in Chinese and English, core maintenance capability in foreign military is what is mentioned as core support capabilities referred to herein. For the US military research for core maintenance capabilities started earlier. (it began to explore related from the 1980s) Therefore this article takes the US military research as an example.

"Core maintenance capability" first appeared in the "United States Code", Vol. 10 in 2464, which was enacted by Congress in 1984, which explicitly stipulates that the core logistics workload determined by the Secretary of Defense must not be contracted out. Since then, the term has been amended several times in the Army Ordinance, Department of Defense instructions, Marines command, but the main idea remained the same connotation.

"USC" Volume 10, 2464 states: In order to ensure timely and effective response to national defense mobilization, national defense emergency situations and other urgent needs, it is necessary for the Department of Defense to have a government-owned, government-run central logistical capacity (including: equipment and facilities the government owned and operated by the government) in order to ensure that you have a stable and controlled source of technical competence and resources. Based on the core code, Secretary of Defense is responsible for determining the core logistics capabilities described in the above code and the workload to maintain those capabilities necessarily. The "core logistics capabilities" determined by the defense minister must include the necessary ability to maintain and repair these weapons systems and other military equipment. 
Army regulations AR750-1 "Army equipment maintenance policy" said: 'Core is Army weapons systems and steady demand ability formed in the Department of Defense (DOD) base to maintain and guarantee to meet the combat readiness Joint Chiefs of Staff (JCS) emergency scenarios. This Ordinance stipulates that core depot maintenance capabilities should include the ability to ensure technical provisions for securing prepared by a minimum of facilities, equipment and skilled personnel necessary to control sources. Regulations require that equipment development department (MATDEV) must develop the core logistics ability to repair new weapon systems the government achieves and operates within four years after the initial operational capability forms.

"Depot maintenance core capabilities judgment process" is described in DOD instructions DODI 4151.20 that in order to possess prepared and controlled technical capacity and resources to source when responding national defense mobilization, defense emergencies and other emergency requirements, the Department must possess depot maintenance capabilities on facilities the government owned and run. This directive requires the units of DOD to determine the effective core capacity required and the amount of work required to maintain core capacity by the core capability requirements determination process. Units of DOD computes core capabilities necessarily and depot maintenance workload to maintain these capabilities necessarily, then combine all these values to determine the total DOD core requirements.

Marine Crops defined core as "The minimal required facilities, equipment and technical personnel for determining a ready, controlled source of technical knowledge required to minimize the risks that is used to keep the ability to meet the requirements of the Joint Chiefs of Staff (JCS) emergency scenario readiness and sustainability internal organizational base. " Core is expressed as the minimum of capacity needed meeting this definition which is represented by direct labor hours (DLH). Core holding force is a readiness enabling factor which makes combat equipment support meet the needs of the total strength fast, flexible and fully.

(2) Domestic Research Status

Research on the core support capabilities of our army has just begun, mainly follow-up study on the US core service capabilities. And now for the core support capabilities of the equipment system there is none of an accepted definition and the definition given in academia mostly based on the core military capabilities of our military in the new century.

Wang Jialong [4] present that the core logistics support capability is the ability to win local wars in conditions of informationization and the ability to complete the core mission which promotes military logistical preparations. Hu Fuwen [5] got inspiration from core capability of the enterprise and described the connotation of core security capabilities based on the army's logistics support practical as the ability which makes fundamental, decisive capacity and long-term effects to safeguard military operations and includes emergency-mobile support capabilities, integrated support capabilities and accurate support capabilities. Bian Haoyue [6] gave the definition that core support capability is that ability to improve security to win local wars under conditions of informatization which follows the law of power generation, takes logistical preparations for military struggle as traction, plans scientifically, take initiatives as called for and innovatives practice. Li Wanjun [7] hold the opinion that the core security capability is the ability of winning the informationization local wars which is based on the strategic thinking 'taking enhancing the capability to win local wars under conditions of informationization as the core" in the logistical support capabilities in diverse military tasks guarantee of the army, especially the ability which plays a fundamental and basic role in ensuring to win.

\subsection{Evaluation Parameters.}

(1) Foreign Research Status

For the study of the parameters system of core support capabilities, it just started abroad. But related research on comprehensive evaluation parameter RMS from foreign military can be borrowed. The US Department of Defense Joint Chiefs of Staff JCS Pub1-02 publication specified in the two pillars of military capability, that is readiness capability and continuing combat capability. Comprehensive evaluation parameter corresponding readiness capability has operational readiness (Por), operational availability (Ao) $[8,9]$. Operational availability is a commonly used metric, and 
attached great importance of the US which is divided into intrinsic availability, up availability, operational availability and use of time rio. The corresponding comprehensive evaluation parameters of continuing combat capability are reliability of mission $(\mathrm{Rm})$ and credibility $(\mathrm{Do})[10,11,12]$. The former is for the system can not be repaired in carrying out its mandate and the latter is for continuous use system.

(2) Domestic Research Status

During 'the Tenth Five-Year' period, the army carried out the relevant work of "the two into two forces" and put forward the standards of construction and implementation measures of comprehensive evaluation. But the method involved is mainly based on troops' actual statistical data which is gotten by using expert scoring ways and the evaluation parameters are almost static parameters. During 'the Eleventh Five-Year' period, the dynamics integrated parameters [13] proposed for the level of basic equipment combat unit, the smallest task units and equipment combat unit are equipment readiness rate, operational availability and task completion probability and for the security system [14] are the probability of task completion and time of security services. But the parameter system for equipment SoS has not been established.

\subsection{Evaluation Method.}

When using simulation platform to carry out research of SoS, it can reduce the number of basic work and improve the degree of reuse of models and the comparability of research results. Therefore, foreign research institutions take the study of simulation platform of SoS quite seriously and put a lot of research and development strength into exploding. Thus they have achieved some results and create the conditions for the theoretical modeling and research methods of SoS. There are many systems of foreign SoS, but most of them are far away from the equipment SoS. System modeling tools can be applied to the study on the equipment SoS are Framework, Teleogic and Core and common platforms are Swarm, Repast and Netlogo. Take the US as an example, models can be used for analysis of the SoS-level integrated safeguards are SoS analysis tool (SoSAT) and SoS availability model (SoSAM).

SoS analysis tool (SoSAT) is developed by the Sandia national laboratory and the object it oriented is brigade level ground forces. It is constituted by a set of software tools that can provide the following functions: (1) Simulation of any SoS; (2) Multi-stage mission simulation; (3) Provide data to evaluate the performance of the system; (4) Support business decisions and commercial trade. The basic model of SoSAT include: system elements reliability failures, loss of the use of consumables, detailed maintenance activities and inventory replenishment and the advanced models include: battle damage model, network model and predict and health management.

System availability model (SoSAM) is a SoS analysis model developed by the US Army Materiel Systems Analysis Action center (AMSAA). SoSAM is developed by Arena simulation software and can do simulation for a three-day fighting failure, repair and maintenance activities of combat unit of Future Combat Systems. In addition to a variety of maintenance parameters, SoSAM can also provide instant operational availability at all levels of system.

From the current data, the evaluation parameter model for the core security equipment system capacity has not been established interiorly. But the established parameters model of the basic combat unit and equipment combat unit can be used for reference. Current research methods towards basic combat unit floors above are analytic method and simulation method [15] [16], as well as integrated application of these two methods.

\section{Summary}

\subsection{Summary of Current Research .}

Outdoor research started from the evaluation of combat readiness capability and sustained combat capability and the RMS established an industry-recognized integrated parameters system and evaluation model, especially evaluation model about combat readiness capability. For different types of equipment, detailed readiness metrics, definitions and measurement formula have been given. A parameter system has also been established and been applied to the simulation evaluation system by 
modeling specificly. These simulation evaluation system experiencing combat testing, has a very high credibility, which has major implications for military research on the core support capabilities.

In recent years, there is a lot of domestic research work about RMS evaluation of security object system carried out. But most of them is for a lower level of security object system including the single and basic combat unit of such equipment and the research on equipped combat units and equipment $\mathrm{SoS}$ is less much. And the research on the ability of protecting the core of equipment system is still in the stage of determining concept and establishing the system of the evaluation parameters, not even form an accepted definition of core support capabilities and parameters proposed are also only the top parameters, not specific to the operational level.

\subsection{Recommendations of the Research of SoS in Future.}

Research trending shows that the current domestic research in this area is still only in its infancy, future research should focus on the following four aspects to be considered.

(1) Focus on military-related theoretical results. US military's research on support capabilities of core started earlier, so we can learn the US from definition of core security capabilities and its development process and summarize lessons learned, avoid detours combined with the actual army and expand their research.

(2) Strengthen basic research. Core support capacity is built upon equipment SoS. Considering the emergence and loosely coupled of the equipment SoS, it is different from combat units and basic equipment combat unit. So when facing the core security equipment SoS capacity issues, a comprehensive parameter similar to guarantee effectiveness need to be established. Then qualitative requirements of combat support equipment $\mathrm{SoS}$ should be turned into system specific parameters.

(3) Attach importance to system research on evaluation problem. Use system engineering principles to overall plan the core equipment system capacity issue and fully considerate the relationship between the different layers of the parameters and between the same layer parameters without missing to make evaluation rigorous and specification.

(4) Deepen the research on security simulation technology. Pay close attention to the linkage changes of the security simulation system brought about changes of the parameters and select simulation models recognized within the industry. Put emphasis on simulation data analysis methods and introduce exploratory analysis, data farming and computational experiments and other foreign advanced technology and obtaine the most central equipment system parameters of security equipment SoS capacity on the basis of simulation results.

\section{References}

[1]. Dongsheng Yang, Weiming Zhang, Zhong Liu. System-of-system in the information era: Concept and definition [J]. Science Press. Vol. 30 (2009) No. 3, p. 18-26.

[2]. Eisner H., Marciniak J., McMillan R. Computer-Aided System of System Engineering. Proceeding of the 1991 IEEE International Conference on System, Man, and Cybernetics.University of Virginia, Charlottesville, 1991, VA.

[3]. Weixin Jin, Tianyuan Xiao. Research on the combat SoS complex network [J]. Complex Systems and Complexity Science. Vol. 6 (2009) No. 4, p. 12-25.

[4]. Jialong Wang. Provide strong support to improve core logistical support capabilities [J]. Grassroots Construction. (2008) No.5, p. 26.

[5]. Fuwen Hu, Jinlei Feng. Several questions about the core logistical support capabilities of military [J]. Logistics Academic. (2010) No.1,p. 37-39.

[6]. Haoyue Bian, Zengqing Yang. Promote the core logistics support capability in the guide of scientific development [J]. Logistics Academic, (2010) No.4, p. 7-10.

[7]. Wanjun Li, Pinglu Zhu. Rational thinking of core logistics support capabilities construction in conditions of informationization [J]. Logistics Academic, (2010) No.5, p. 28-31. 
[8]. M. Thompson. Lower Confidence Limits and a Test of Hypotheses for System Availability. IEEE Transactions on Reliability, R-15, No.1, May 1966, p. 32-36.

[9]. Operational Availability Handbook-A Practical Guide for Military Systems. Sub-Systems and Equipment [S]. 2003.

[10]. Zhang Weijin, Kang Rui, Guo Linhan. Study on military equipment support modeling and simulation [J]. Journal of Chinese Journal of Aeronautics. Vol. 18 (2005) No. 2, p. 142-146.

[11]. Seung C Chay, Joseph G Hendeson. A Performance Measure for a Yhsic Avionic System: Mission Dependent Availability [C]. Reliability and Maintainability Symposium. (1989),: p.191-196.

[12]. Harold S Balaban, Robert T Brigantic, Samuel. A Wright A Simulation Approach to Estimating Aircarft Mission Capable Rates for the United State Air Force [C]. Proceedings of the 2000 Winter Simulation Conference. USA Orlando, 2000, p.1035-1042.

[13]. Huijuan Feng: Research on RM modeling of equipment combat unit support object system [D]. (Doctor, Ordnance Engineering College, Chinese, 2010) p. 55-83.

[14]. Wenwu Liu: Research on modeling of support system based on ontology [D]. (Doctor, Ordnance Engineering College, Chinese, 2011)

[15]. Huijuan Feng. Mission reliability simulation of aggregated equipment combat units for mission of mobile aerial defense [J]. Journal of System Simulation. Vol.22 (2010) No. 7, p. 1728-1732.

[16]. Wei Zhang. Equipment support simulation modeling and system prototype development [D]. (Doctor, Ordnance Engineering College, Chinese, 2013) p.131-149. 